NASA Technical Memorandum 106231

AIAA-93-3065

\title{
Averaging Techniques for Steady and Unsteady Calculations of a Transonic Fan Stage
}

M.L, Wyss

University of Cincinnati

Cincinnati, Ohio

and

R.V. Chima and D.L. Tweedt

Lewis Research Center

Cleveland, Ohio

Prepared for the

24th AIAA Fluid Dynamics Conference

sponsored by the American Institute of Aeronautics and Astronautics

Orlando, Florida, July 6-9, 1993

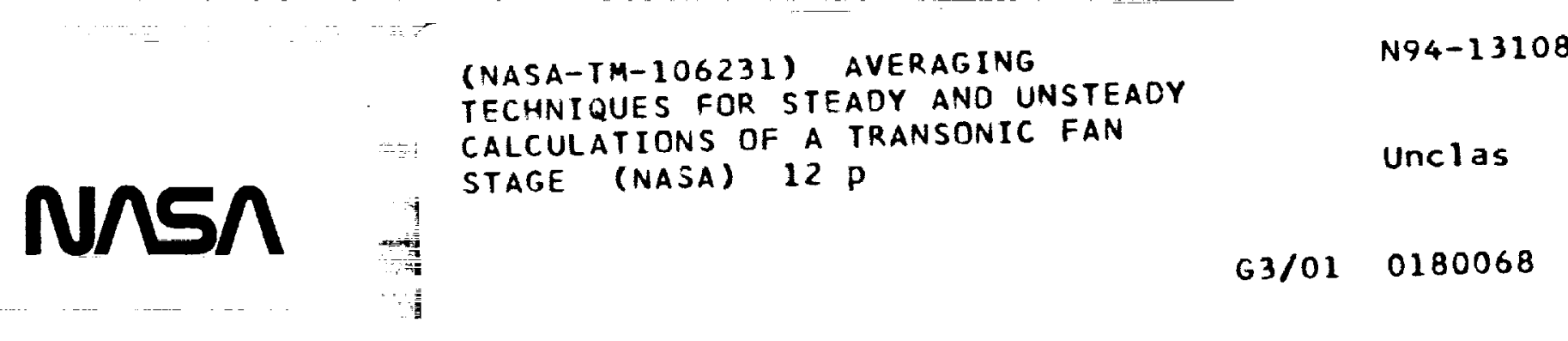




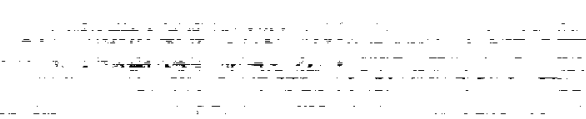

$=2-1$

a

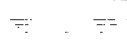

(n)

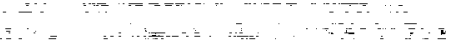

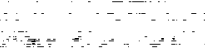

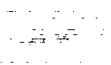

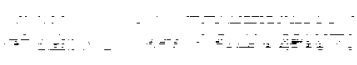

$\cdots$

$\therefore-1-1-$

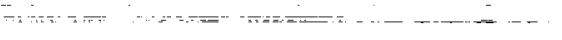

$=$

$-1$

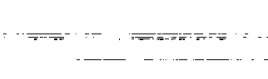

$\because \quad \cdots+\cdots$

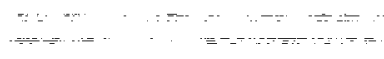

$=$

$-\ldots$

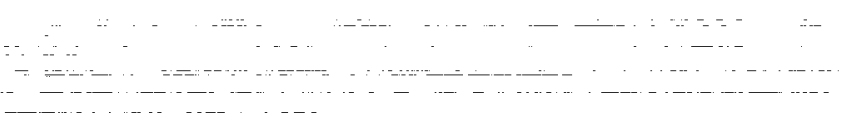

$=-1$

- . - . -

a

-

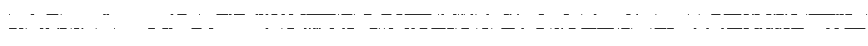

a

-

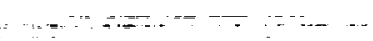

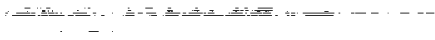

- n.....

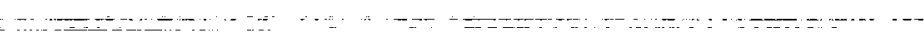

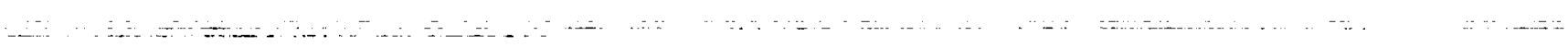

$-\cdots+\cdots+\cdots+\cdots$

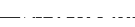

-

$\cdots$ 


\title{
AVERAGING TECHNIQUES FOR STEADY AND UNSTEADY CALCULATIONS OF A TRANSONIC FAN STAGE
}

\author{
M. L. Wyss * \\ University of Cincinnati, Cincinnati, Ohio \\ R. V. Chima* and D. L. Tweedt \\ NASA Lewis Research Center, Cleveland, Ohio
}

\begin{abstract}
It is often desirable to characterize a turbomachinery flow field with a few lumped parameters such as total pressure ratio or stage efficiency. Various averaging schemes may be used to compute these parameters. This paper describes and compares the momentum, energy, and area averaging schemes. The schemes were compared for two computed solutions of the midspan section of a transonic fan stage: a steady averaging-plane solution in which average rotor outflow conditions were used as stator inflow conditions, and an unsteady rotor-stator interaction solution. The solutions were computed on identical grids using similar Navier-Stokes codes and an algebraic turbulence model. The unsteady solution is described, some unsteady flow phenomena are discussed, and the steady pressure distributions are compared. Despite large unsteady pressure fluctuations on the stator surface, the steady pressure distribution matched the average unsteady distribution almost exactly. Stator wake profiles, stator loss coefficient, and stage efficiency were computed for the two solutions with the three averaging schemes and are compared. In general, the energy averaging scheme gave good agreement between the averaging-plane solution and the time-averaged unsteady solution, even though certain phenomena due to unsteady wake migration were neglected.
\end{abstract}

\section{INTRODUCTION}

Numerical analyses of three-dimensional steady flows in isolated turbomachinery blade rows can now accurately predict blade row performance in reasonable computer times $[1,2,3,4,5]$. It is thus reasonable to consider approaches for calculating the performance of multiblade-row machines.

One approach is to compute unsteady rotor-stator interaction directly, integrating the time-averaged performance from the unsteady solution. This was done

\footnotetext{
- Member AIAA

Copyright $(1993$ by AIAA, Inc. No copyright is asserted in the United States under Title 17, U.S. Code. The U.S. Government has a royalty-free license to exercise all rights under the copyright claimed herein for Governmental purposes. All other rights are reserved by the copyright owner.
}

in three dimensions by Rai [6] with excellent results, but solution times were long. In more recent $3-D$ unsteady calculations, solution times have been greatly reduced $[7,8]$. However full 3-D unsteady calculations still require substantial computer resources.

Several researchers have computed unsteady rotorstator interaction in two dimensions. A 21 /2-stage compressor was modeled in [9], and [10,11, 12] have all modeled single-stage machines. Here solution times are more tractable, but results still require time averaging for interpretation.

Another approach is to model a multistage machine as steady in some average sense. Adamczyk's average passage model provides a formal mathematical framework for this type of analysis and has been used very successfully [2]. Other researchers $[3,4,5]$ have used a more ad hoc approach in which the solution is circumferentially averaged at a plane between blade rows. This averaging-plane approach has given useful results in many instances, but raises the question of how to average the solution for the best results.

In the present work (originally described in [13],) the midspan section of a transonic fan stage designated NASA stage $67[14,15,16]$ was analyzed using both a steady averaging-plane approach and an unsteady rotor-stator interaction approach. Three averaging schemes, referred to as the momentum, energy, and area averaging schemes were used to average the steady solution between the rotor and stator. The unsteady solution did not require averaging between the blade rows but did require averaging to show timeaveraged quantities as a function of space (e.g., surface pressure distribution) or to show spatially-averaged quantities as a function of time (e.g., stage efficiency). The unsteady solution was considered a standard by which to evaluate the three averaging schemes used in the steady solutions. Comparisons were made between unsteady and steady pressure distributions, wake profiles, stage adiabatic efficiency, and stator loss coeffcient. In general, the energy averaging scheme gave the best agreement between the unsteady and steady solutions. Qualitative comparisons of rotor wake migration were made with experimental measurements made by Hathaway et al. [16]. 


\section{FAN STAGE}

Calculations were made for the 50-percent mass-flow streamline of a transonic axial flow fan stage designated NASA stage 67 . The fan was designed for a rotational speed of $16043 \mathrm{rpm}$ and a mass flow of 34 $\mathrm{kg} / \mathrm{sec}$. The rotor and stator are separated axially by about 85 percent of the rotor chord at midspan in order to minimize noise. Because of the large interblade spacing, the unsteady effects on the stator are mostly due to interaction with the rotor wakes. Although this allows wake-generated unsteadiness to be studied independently of acoustic effects, it also means that the conclusions drawn here regarding averaging schemes do not necessarily extend to closely coupled blade rows.

The midspan radius is about $19.3 \mathrm{~cm}$ and is nearly constant. The stage has a significant amount of hub and tip convergence, such that the annular area decreases by 22 percent through the rotor and by 27 percent through the stage. The radius change and annulus convergence were modeled using the quasi-3-D analysis described in the following section. The rotor has 22 multiple-circular-arc blades designed for purely axial inflow. The stator has 34 double-circular-arc blades designed to produce purely axial outflow. (A controlled diffusion stator was also tested in $[14,16]$ but was not considered here.)

The fan has been extensively tested using both conventional aerodynamic probes and laser anemometry. The ensemble average and variance of the laser data have been analyzed to compute the rotor-wakegenerated and unresolved unsteadiness $[14,15,16]$. In the present work, qualitative comparisons were made to the rotor-wake-generated unsteadiness data.

\section{NUMERICAL METHOD}

Steady solutions were made using the RVCQ3D code developed by Chima [17] and unsteady solutions were made using the URSA code developed by Jorgenson and Chima [10,11]. Both codes solve the quasi-threedimensional thin-layer Navier-Stokes equations for a blade-to-blade stream surface and include the effects of rotation, radius change, and stream sheet thickness. The Baldwin-Lomax model was used for turbulent flows. The flow equations were discretized using second-order-accurate finite differences, with thirdorder artificial viscosity added everywhere and firstorder artificial viscosity added near shocks. The equations were solved using an explicit four-stage RungeKutta scheme. Whenever possible, the same numerical parameters (i.e., artificial viscosity coefficients, turbulence model parameters, etc.) were used for both the steady and unsteady calculations.

Circumferentially periodic C-type grids were generated using the GRAPE code [18]. Grid sizes were $303 \times 45$ for the rotor and $307 \times 45$ for the stator. Identical grids were used for both calculations.

Radius change and endwall convergence were mod- eled in the quasi-three-dimensional analysis by assuming that the blade-to-blade flow follows an axisymmetric stream surface of known radius $r$ and normal thickness $h$. The equations were formulated in an $(m, \theta)$ coordinate system, where $m$ is the arc length along the surface, $d m^{2}=d r^{2}+d z^{2}$, and $r=r(m)$ and $h=h(m)$ must be specified. Details of the quasi-3-D formulation may be found in $[10,11,17]$.

The stream surface and radius were extracted from steady 3-D analyses of the rotor (see ref. 1) and the stator (unpublished.) The 3-D solutions were first circumferentially averaged to produce an axisymmetric solution. The mass flow was then integrated as a function of span, and the location of the 50-percent streamline was tracked. Finally the blade profile, radius, and relative distance between neighboring streamlines were interpolated as functions of distance along the streamline. The 50-percent streamline is near midspan where the radius only varies about 3 percent through the machine. The stream surface thickness $h(m)$ varies much like the annulus area, decreasing about 27 percent through the stage.

The steady quasi-3-D code uses a spatially-variable time step and implicit residual smoothing with a CFL number of 5.5 to accelerate convergence to a steady state. Stage calculations were made by solving an isolated rotor and then averaging the exit flow. The average total pressure, total temperature, and tangential velocity were specified as inlet boundary conditions for an isolated stator solution. The stator exit static pressure was varied iteratively until the stator and rotor mass flows matched. Solution times were about 3 minutes per blade row on a Cray Y-MP.

The unsteady quasi-3-D code uses a constant time step subject to a CFL limit of about 2.8. Spatially varying implicit residual smoothing was used to increase the maximum CFL number to about 12 while retaining second-order accuracy in time [11]. The rotor and stator grids overlap by one point at an interface between the blade rows. The interface was updated by a nonconservative interpolation of the flow variables. Two rotor and three stator blades were solved to approximate the $22: 34$ blade count of the actual stage. It took 1126 iterations at 0.52 seconds per iteration on the Cray Y-MP for two rotor blades to pass three stator blades. This time interval will be referred to as a blade passing interval. Stator lift coefficients were roughly periodic after about eight blade passing intervals and fully periodic after 16 . Results are shown after 21 blade passing intervals (almost two rotor revolutions) which took 3.4 hours on the Cray.

\section{AVERAGING SCHEMES}

It is often desirable to characterize a complicated flow with a few lumped parameters. For example, a computational analysis of a fan stage might specify constant $p_{0}$ and $t_{0}$ at the inflow boundary and constant 
$p$ at the exit, and a turbomachinery designer would want to know the overall efficiency of the stage. In a real machine, each of these quantities varies in both space and time so that it becomes necessary to develop representative averages.

In two dimensions any two independent kinematic properties (velocity components) and two independent thermodynamic properties completely characterize the fluid state. As such, four properties may be averaged to satisfy four desirable characteristics of the system such as global conservation of mass, momentum, and energy. Since flow properties are related nonlinearly, the average properties may not necessarily satisfy other characteristics that were satisfied by the original system; that is, information is lost through the averaging process. It thus becomes necessary to decide what information must be retained for a particular application and to devise averaging schemes accordingly.

Any arbitrary quantity can be averaged in a mathematical sense; however, averages of some quantities have more physical significance than others. Flow properties are often categorized as being either intensive or extensive. Intensive properties are single valued at each point in the flow. Thermodynamic variables such as pressure and density are examples of intensive properties. Extensive properties depend on the mass or volume (i.e., the extent) of a system and are often defined as an integral of an intensive property over its respective mass or volume. Mass $=\int \rho d V$ and force $=\int p d A$ are examples of extensive properties. Extensive properties have the characteristic that they may be summed over the parts of a system to give a total value of the property. This characteristic makes it desirable to use extensive properties for flow-field averages.

Three averaging schemes are described below. They are referred to as the momentum, energy, and area averaging schemes, or MAS, EAS, and AAS, respectively.

\section{MOMENTUM AVERAGING SCHEME (MAS)}

The MAS is the most rigorous of the three schemes described here and serves as the basis for the other two. For 2-D adiabatic flow it is equivalent to the mixed-out average often referred to in turbomachinery literature.

The flux terms in the Euler equations are intensive properties that may be integrated over their respective areas to produce extensive properties. The unsteady two-dimensional Euler equations are given by

$$
\frac{\partial q}{\partial t}+\frac{\partial F}{\partial x}+\frac{\partial G}{\partial y}=0
$$

where

$$
q=\left[\begin{array}{l}
\rho \\
\rho u \\
\rho v \\
e
\end{array}\right] \quad F=\left[\begin{array}{l}
\rho u \\
\rho u^{2}+p \\
\rho u v \\
u(e+p)
\end{array}\right] \quad G=\left[\begin{array}{l}
\rho v \\
\rho u v \\
\rho v^{2}+p \\
v(e+p)
\end{array}\right]
$$

and

$$
e+p=\rho\left(C_{v} T+V^{2} / 2\right)+\rho R T=\rho h_{0}
$$

Assuming steady flow and integrating in $y$ over the pitch $l$ of a turbomachine gives

$$
\frac{\partial}{\partial x} \int_{0}^{l} F d y+G(l)-G(0)=0
$$

If the flow is periodic over $l$, then $G(l)-G(0)=0$, and

$$
\int_{0}^{1} F d y=\text { constant }
$$

Applying (2) to a uniform flow (denoted by an overbar) gives.

$$
\frac{1}{l} \int_{0}^{l} F(\rho, u, \ldots) d y=\overline{F(\rho, u, \ldots)}=F(\bar{\rho}, \bar{u} \ldots)
$$

This expression may be used to define an average flow by solving for $\bar{\rho}, \bar{u}, \ldots$ in terms of the local integrals $I_{c}, I_{x}, \ldots$ as follows:

$$
\begin{aligned}
& I_{c}=\frac{1}{l} \int_{0}^{l} \rho u d y=\bar{\rho} \bar{u} \\
& I_{x}=\frac{1}{l} \int_{0}^{l}\left(\rho u^{2}+p\right) d y=\bar{\rho} \bar{u} \bar{u}+\bar{\rho} \\
& I_{y}=\frac{1}{l} \int_{0}^{l} \rho u v d y=\bar{\rho} \bar{u} \bar{v} \\
& I_{e}=\frac{1}{l} \int_{0}^{l} \rho u h_{0} d y=\bar{\rho} \bar{u} \overline{h_{0}}
\end{aligned}
$$

The average quantities are given by

$$
\begin{aligned}
\bar{\rho} & =I_{c} / \bar{u} \\
\bar{u} & =\left(I_{x}-\bar{p}\right) / I_{c} \\
\bar{v} & =I_{y} / I_{c} \\
\overline{h_{0}} & =I_{e} / I_{c}
\end{aligned}
$$

Using the definition of $\overline{h_{0}}$,

$$
\overline{h_{0}}=\frac{\gamma}{\gamma-1} \frac{\bar{p}}{\bar{\rho}}+\frac{\bar{u}^{2}+\bar{v}^{2}}{2}=\frac{I_{e}}{I_{c}}
$$

and eliminating $\bar{\rho}, \bar{u}$, and $\bar{v}$ using $(8,9$, and 10) gives a quadratic equation for $\bar{p}$. The solution is

$$
\bar{p}=\frac{I_{x} \pm \sqrt{I_{x}^{2}-\left(\gamma^{2}-1\right)\left(I_{x}^{2}+I_{y}^{2}-2 I_{e} I_{c}\right)}}{\gamma+1}
$$

The positive sign is for axial subsonic flow and the negative sign is for axial supersonic flow. Once $\bar{p}$ is known, the remaining quantities may be found directly. 
Equations (4-13) define a complete set of average properties. Since the average flux and average properties are constant in $x$ (eq. 2,3), these properties represent the uniform flow far downstream of a cascade after the blade wakes have mixed out, and thus the averaging scheme is the so-called mixed-out average. Far downstream, viscous dissipation has caused all velocity gradients in the wakes to decay to uniform conditions with a subsequent increase in entropy and decrease in total pressure.

The Euler equations (1) apply to 2-D adiabatic flow, which may not be the case in a general turbomachinery problem. Nevertheless, equations (4-13) may still be used as an averaging scheme. The MAS is relatively insensitive to the axial location where the averaging is performed. It accurately represents available thrust but tends to give low efficiencies and high losses, depending on the degree of flow nonuniformity.

\section{ENERGY AVERAGING SCHEME (EAS)}

Total pressure and temperature are commonly measured experimentally with combination probes located fairly close behind turbomachinery blade rows, well before the wakes have mixed out. Behind a rotor, it is generally assumed that the measurements are somehow temporally averaged by the low frequency response of the instrumentation. This temporal average is equivalent to a circumferential average if the rotor speed is constant. Behind a stator, measurements are taken at many locations and are usually mass averaged. Total pressure is an intensive property and a mass average has questionable physical significance. However, mass averaging computed total pressures may give the best comparison with experimental data averaged the same way.

In the EAS the axial momentum integral (5) is replaced with a mass average of the ideal total enthalpy $h_{0 i}=p_{0}^{(\gamma-1) / \gamma}$ (nondimensionalized by some arbitrary reference state):

$$
I_{\mathrm{ei}}=\frac{1}{l} \int_{0}^{l} \rho u h_{0 i} d y=\bar{\rho} \bar{u} \overline{h_{0 i}}
$$

Primitive variables are found from the integrals $I_{c}, I_{\boldsymbol{y}}$, $I_{e}$, and $I_{e i}$ in a manner similar to that used in the MAS, except that a nonlinear equation must be solved:

$$
\bar{p}^{\frac{\gamma-1}{\gamma}} \frac{I_{c}}{\bar{I}_{e i}}+\frac{\bar{V}^{2}}{2 \bar{h}_{0}}-1=0
$$

where $\bar{V}^{2}=\bar{u}^{2}+\bar{v}^{2} . \quad$ It is convenient to define a new variable:

$$
\Phi=\frac{\bar{V}^{2}}{2 \overline{h_{0}}}
$$

Then $\bar{p}$ can be written in terms of $\Phi$ as follows:

$$
\bar{p}=\frac{b(1-\Phi)}{\sqrt{\Phi-c}}
$$

where

$$
b=\frac{\gamma-1}{\gamma} \sqrt{\frac{I_{e} I_{e}}{2}} \text { and } c=\frac{I_{y}^{2}}{2 I_{e} I_{c}}
$$

Equation (15) can be solved for $\Phi$ using Newton iteration. Note that the root $\Phi$ must be between zero $(M=0)$ and one $(M=\infty$.)

The EAS gives a good measure of the local total pressure and temperature, and hence the local adiabatic efficiency and loss for a flow. It usually gives the best comparison with experimental data. Far downstream in a 2-D flow the EAS gives about the same result as the MAS.

In recent unpublished work, Tweedt has used an $e n-$ tropy averaging scheme in which the local specific entropy of the flow is mass averaged instead of the ideal total enthalpy. The entropy averaging scheme is consistent with the second law of thermodynamics, and thus gives the total pressure which best represents the loss at a given axial location. In practice, the energy and entropy averaging schemes usually give similar results. The entropy average was not used in the present work.

\section{AREA AVERAGING SCHEME (AAS)}

The AAS uses conservation of mass (4), and areaweighted integrations of three quantities that might be measured directly by a slow-response probe behind a rotor, static pressure $p$, total pressure $p_{0}$, and total temperature $t_{0}$.

$$
\begin{aligned}
& \bar{p}=\frac{1}{l} \int_{0}^{l} p d y \\
& \bar{p}_{0}=\frac{1}{l} \int_{0}^{l} p_{0} d y \\
& \bar{t}_{0}=\frac{1}{l} \int_{0}^{l} t_{0} d y
\end{aligned}
$$

Primitive variables are found in a straightforward manner, except that the flow angle is found using the MAS. The AAS does not conserve mass, momentum, or energy. It results in the lowest efficiency and highest loss of the three schemes in the present case and is generally the least useful of the three.

\section{RESULTS}

Figure 1 shows relative Mach number contours from the unsteady solution at one instant in time. The inlet Mach number of about 1.2 produces a bow shock that stands ahead of the rotor blade and extends into the passage as an oblique shock. Further downstream, a strong normal shock stands between the rotor blades. Because of the large interblade-row spacing and the transonic flow within the rotor, the stator has little effect on the rotor, and the two rotor passage flows are nearly identical. The rotor wakes do have a large effect on the stator, however, and the three stator passage flows are quite different. Relative Mach numbers in the stator are transonic although absolute Mach numbers 


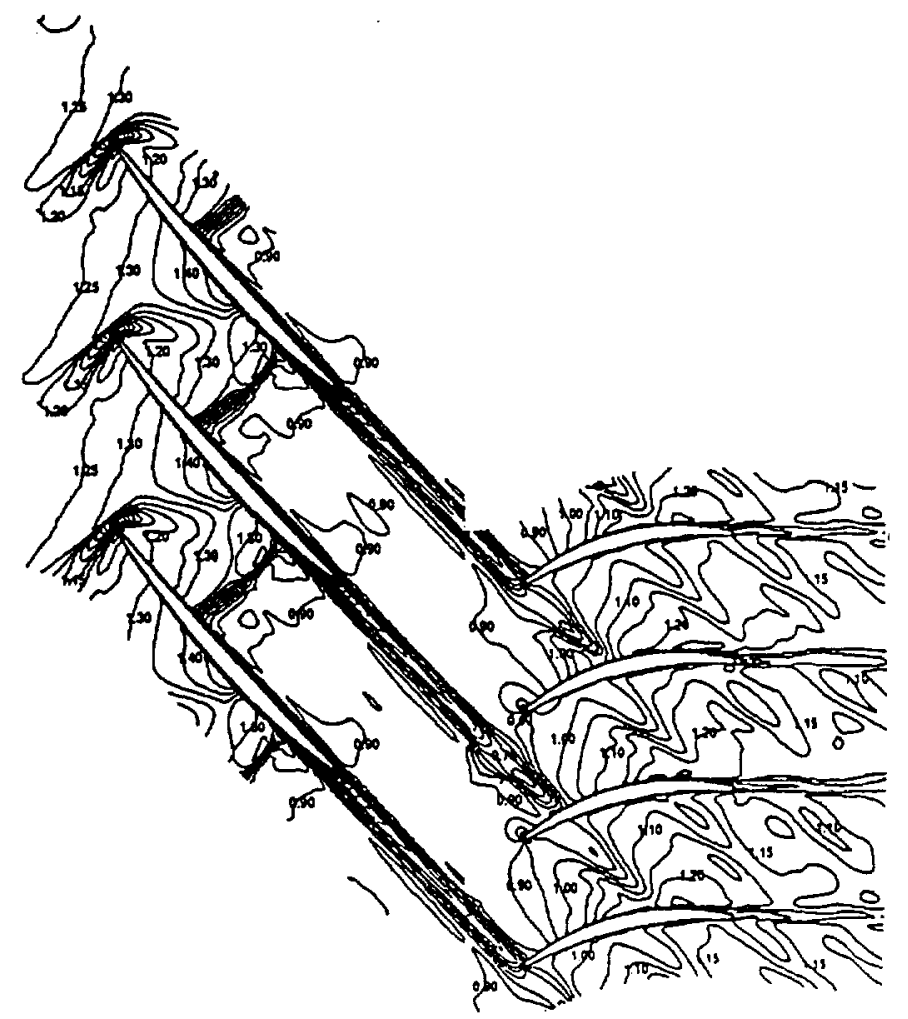

Figure 1.-Unsteady relative Mach number contours.

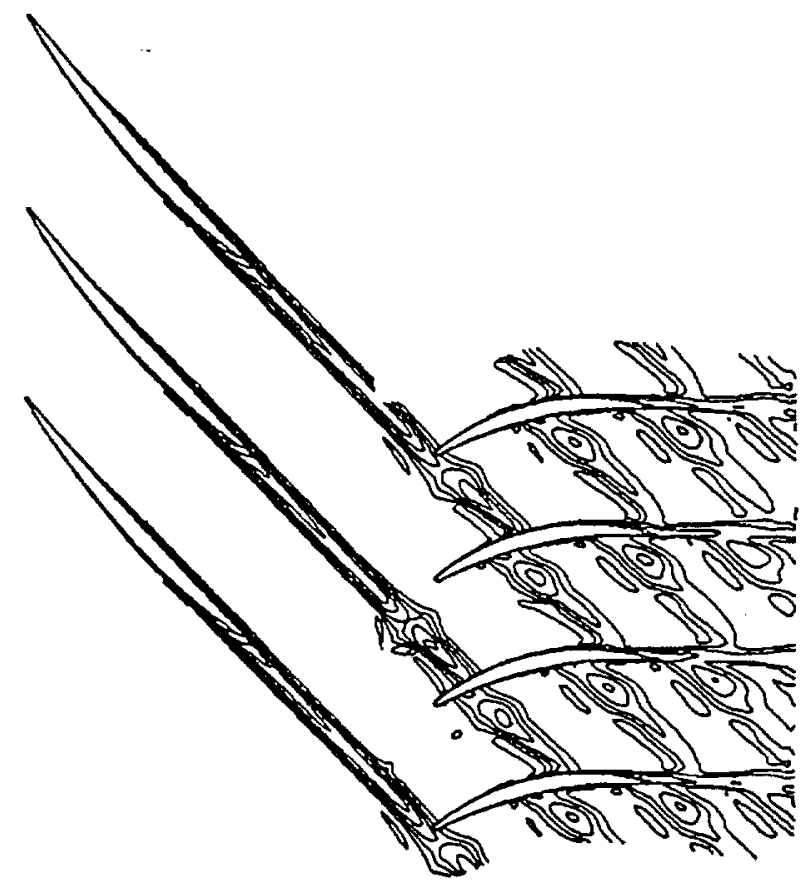

Figure 2.-Unsteady entropy contours.
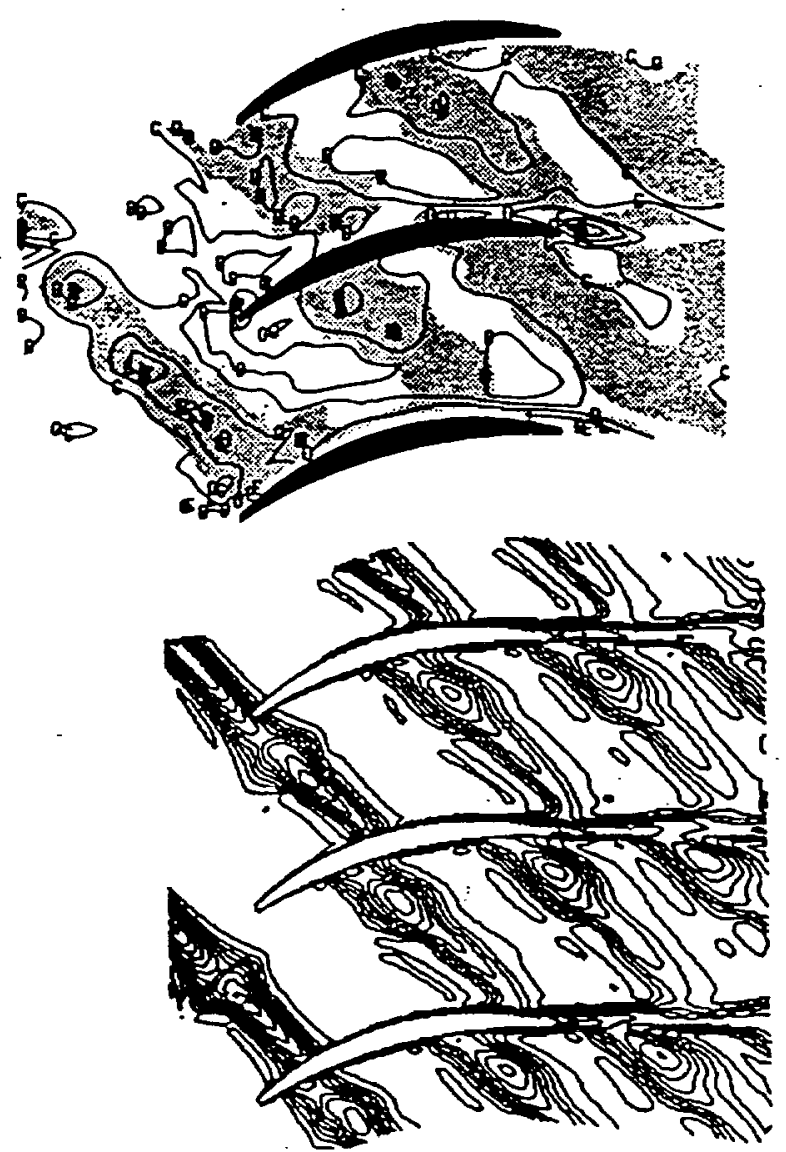

Figure 3.-Experimental contours of turbulent kinetic energy in stator (top) and computed entropy contours (bottom).

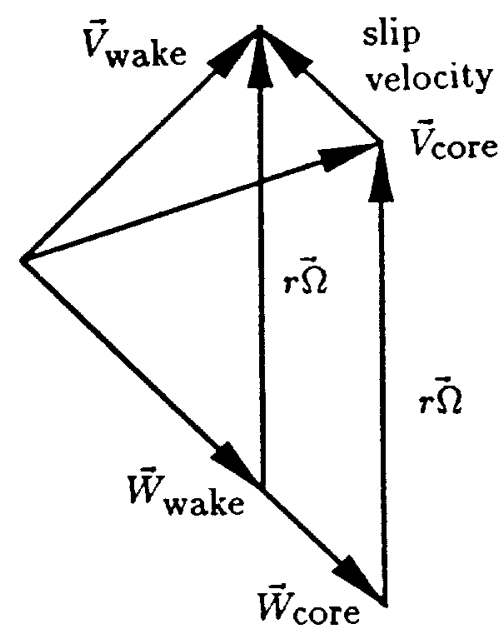

Figure 4.-Velocity triangles for rotor wake and core flow. 


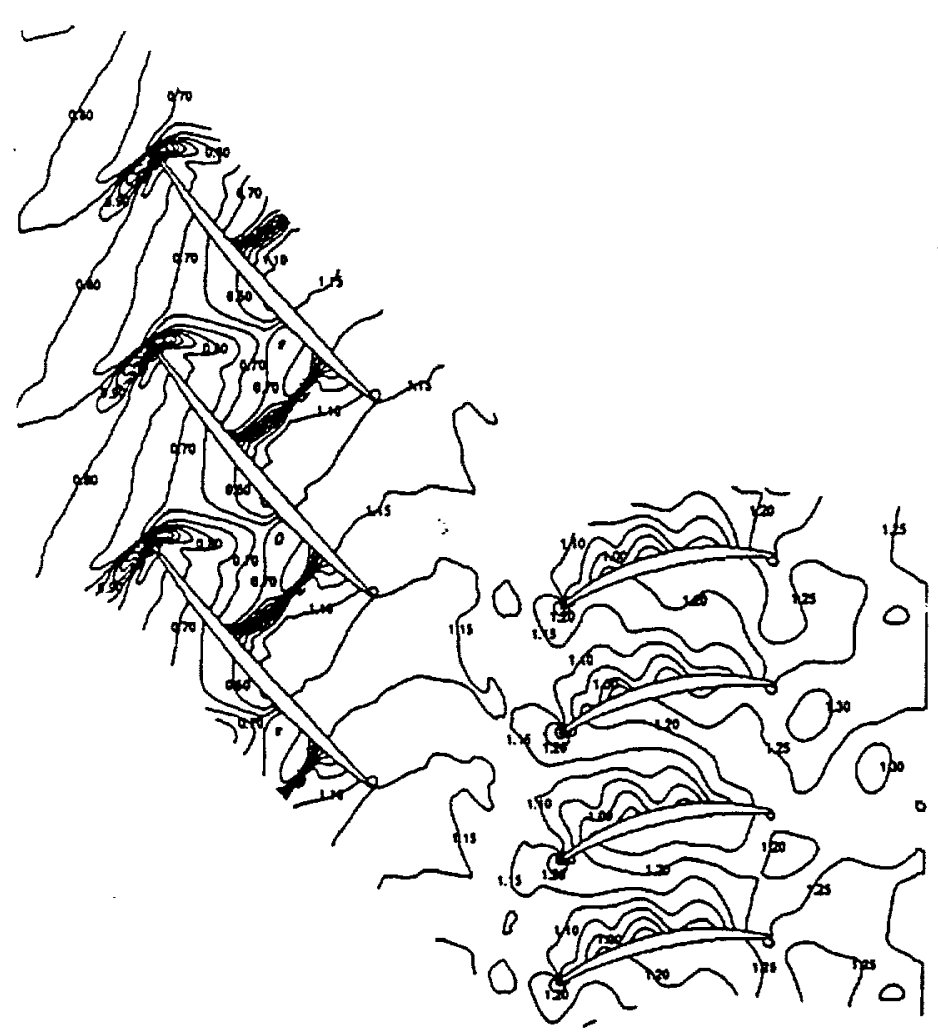

Figure 5.-Unsteady static pressure contours.

(not shown) are between 0.5 and 0.8 . The rotor wakes are chopped by the stator blades and the remnants can be seen vaguely in the passage.

Entropy contours in figure 2 show the rotor wakes more clearly (the shocks produce less entropy than the boundary layers and are not seen at these contour levels). The high-entropy fluid in the center of the rotor wakes migrates towards the pressure side of the stator blades.

The enlargement of the stator region in figure $3 \mathrm{com}$ pares the computed entropy contours with contours of turbulent kinetic energy measured experimentally using laser anemometryby by Hathaway, et al. [16]. Although different quantities are plotted, both give a good indication of the wake positions and agree qualitatively.

The migration of the rotor wakes was originally explained by Kerrebrock and Mikolajczak [19]. The explanation is summarized briefly below. Consider the rotor exit velocity triangles shown in figure 4 . Relative velocities are denoted by $\vec{W}$ and absolute velocities by $\vec{V}$. In the rotor frame of reference the rotor core velocity $\vec{W}_{\text {core }}$ and the rotor wake velocity $\vec{W}_{\text {wake }}$ are roughly parallel to the rotor blade pressure surface. Rotor velocities can be converted to the stator frame of reference by adding the wheel speed, $\vec{V}=\vec{W}+r \vec{\Omega}$.
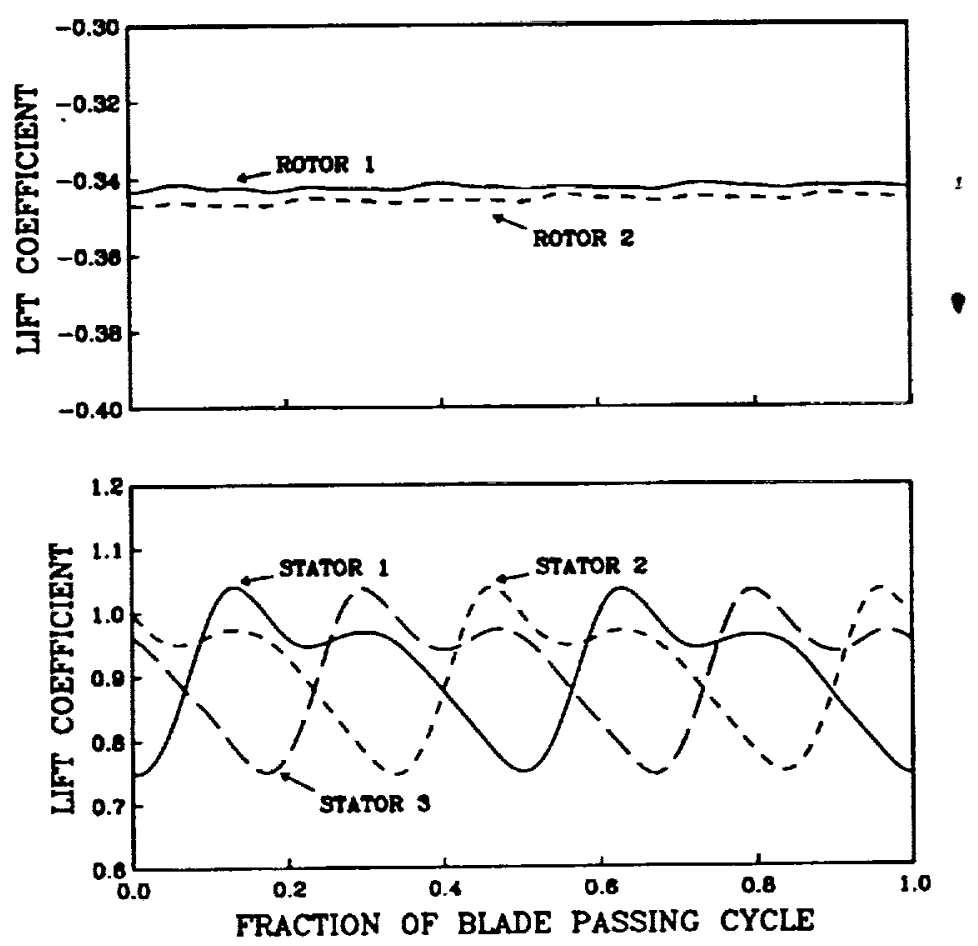

Figure 6.-Unsteady lift history for rotor (top) and stator (bottom).

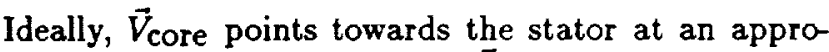
priate incidence angle, leaving $\vec{W}_{\text {wake }}$ with a lower velocity and a higher incidence angle than $\vec{V}_{\text {core. The }}$ difference between $\vec{V}_{\text {wake }}$ and $\vec{V}_{\text {core }}$ is called the slip velocity. This slip velocity carries the rotor wakes towards the pressure surface of the stator blades. The migration of the rotor wakes cannot be calculated with an averaging-plane approach but may possibly be calculated using Adamczyk's average passage model [2] with additional modeling.

Unsteady effects on the pressure field are shown in figures 5-9. Static pressure contours are shown in figure 5. Again the rotor passages are nearly identical but there are large differences between the three stator passages. The pressure surfaces of the stator blades show large differences in loading. The suction surfaces have at least three small regions of low pressure spaced regularly along the blades. These low pressure regions are not clearly associated with the rotor wakes.

Figure 6 shows unsteady lift coefficients for the two rotor blades and the three stator blades during one blade passing interval. The rotor lift varies by less than 1 percent, with three oscillations per blade passing interval due to the three stator blades. The stator lift varies by nearly 30 percent, with two oscillations per blade passing interval due to the two rotor blades. 


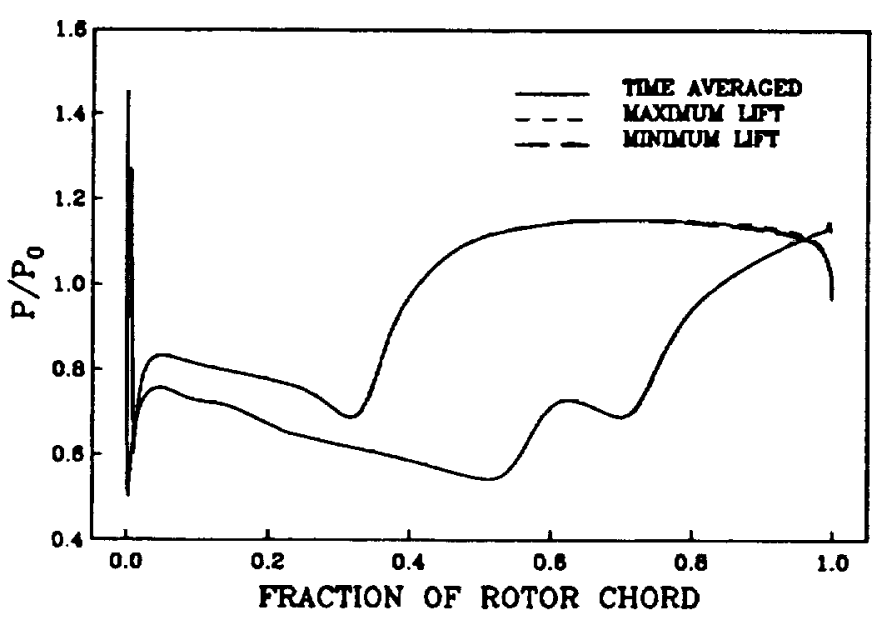

Figure 7.-Rotor pressure distributions at maximum and minimum lift, and time average of unsteady distribution.

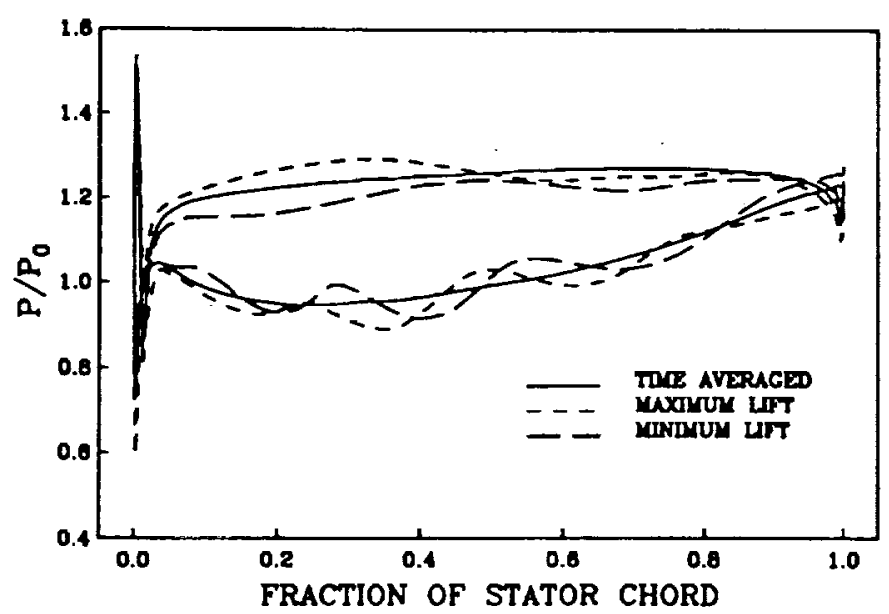

Figure 8.-Stator pressure distributions at maximum and minimum lift, and time average of unsteady distribution.

Figure 7 compares the rotor blade pressure distributions at maximum and minimum lift to a time-averaged distribution made by integrating the unsteady pressure at each point over time. The three curves are virtually identical. A similar plot is shown for the stator in figure 8 . Here, periodic fluctuations about the mean can be seen on both surfaces. On the pressure surface, the fluctuations have a long wavelength. On the suction surface, three distinct minima corresponding to the low pressure regions in the contour plots (figure 5) can be seen.

An interesting discussion of unsteady stator pressures calculated for a compressor stage can be found in the paper by Valkov and Tan [20]. They proposed that the pressure surface fluctuations are caused by unsteady vortices formed on either side of the rotor wakes as they impinge on the stator pressure surface. They also proposed that the suction surface fluctuations are caused by small vortices formed as the rotor wakes

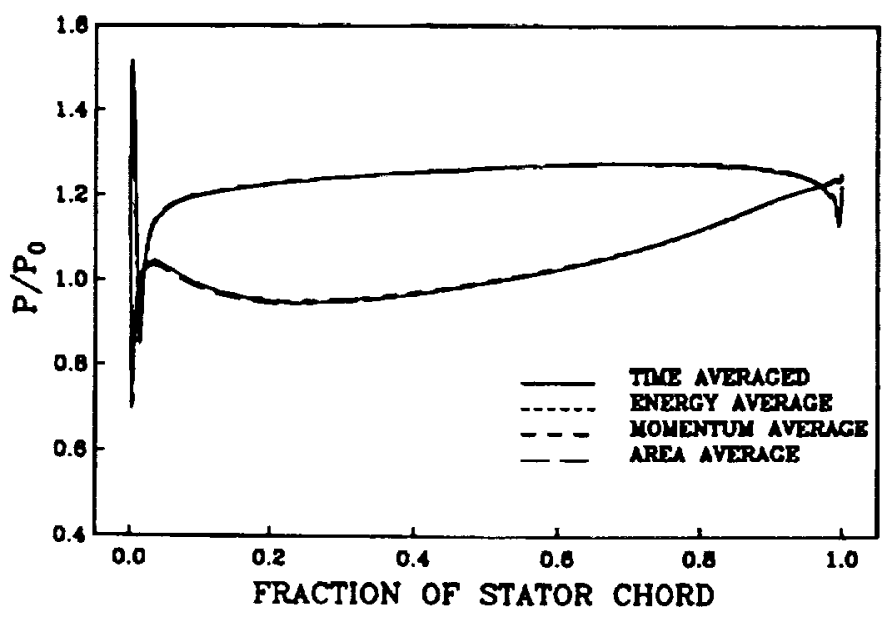

Figure 9.-Comparison of steady and time-averaged unsteady stator pressure distributions (all averaging schemes).

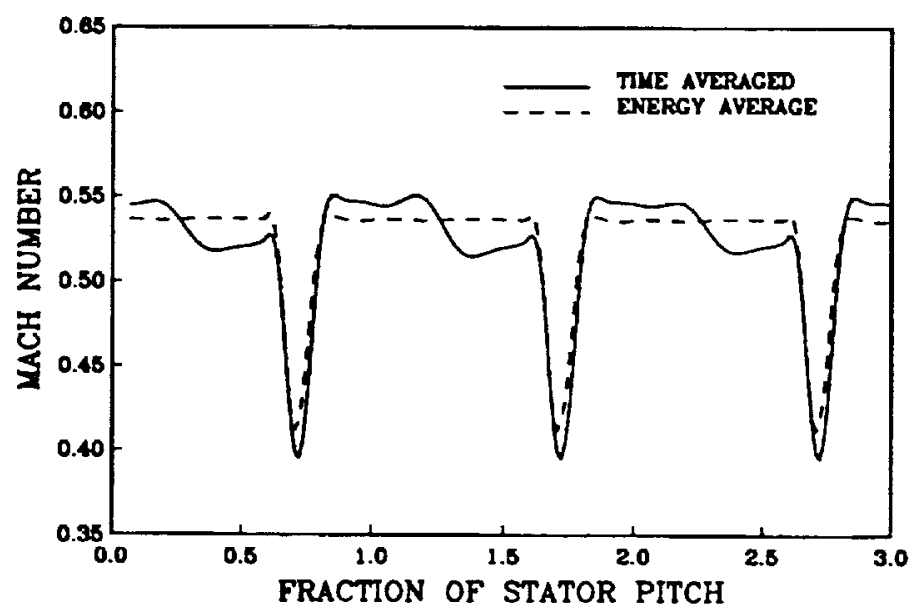

Figure 10.-Comparison of steady and time-averaged unsteady Mach number distributions across stator wake (energy averaging scheme).

pass over the stator leading edges at a high relative incidence. These small vortices convect with the slow boundary layer flow on the suction surface and thus do not correlate with the wake locations. Although neither of these phenomena has been observed directly in the present work, the explanation is plausible. The large pressure fluctuations do seem to be a direct result of viscous interaction between the rotor wakes and the stator boundary layers and could be a significant source of noise in turbomachinery. They are strictly an unsteady phenomena that cannot be predicted with a steady analysis.

Figure 9 compares the time-averaged unsteady stator pressure distribution with steady averaging-plane results made using each of the three averaging schemes. Despite the large unsteady pressure fluctuations in the stator, the time-average stator pressure distribution agrees almost exactly with the pressure distribution predicted by the steady analysis, regardless of the av- 


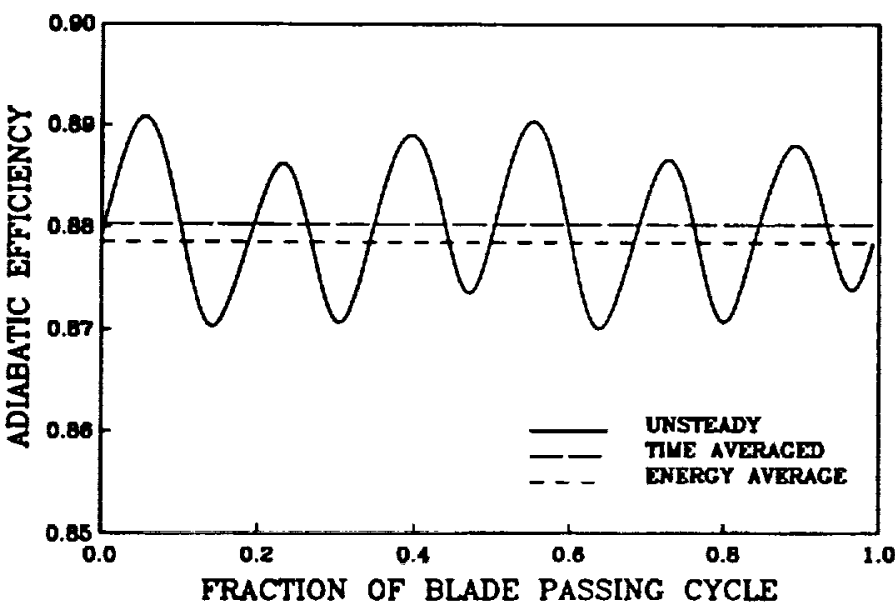

Figure 11.-Stage adiabatic efficiency (energy averaging scheme.)

eraging scheme used. It is both surprising and encouraging that the average pressure distribution can be predicted so closely with a steady analysis.

All of the considerations raised earlier regarding spatial averaging of a flow field also apply to temporal averaging. Again, nearly any quantity can be integrated in time with varying degrees of physical significance. In figures 7-9 for example, surface pressures were integrated in time to produce average pressure distributions. For the remaining results, unsteady stator exit conditions were first spatially averaged using each of the three schemes. Each scheme gives a complete but different vector of the average conservation variables $\bar{q}$ (eq. 1) at each point in time. To integrate these quantities in time, the integrands used for the EAS were constructed from $\bar{q}$ and integrated in time regardless of the averaging scheme used to generate $\bar{q}$ originally. It is by no means clear that this is the best way to time average unsteady solutions.

Figure 10 compares the time averaged unsteady Mach number profile at the stator exit with the steady averaging-plane result made using the EAS. The profiles agree closely across the wake but not across the core. The average unsteady results show high Mach numbers near the suction side of the blade and low Mach numbers near the pressure side resulting from the migration of the incoming rotor wakes. The steady profile is roughly through the middle of the time-averaged unsteady profile. The irregular shape of the unsteady stage exit profile cannot be modeled with an averagingplane approach.

The stage adiabatic efficiency was computed using:

$$
\eta_{\mathrm{ad}}=\frac{\left(p_{03} / p_{01}\right)^{\frac{\gamma-1}{r}}-1}{\left(t_{03} / t_{01}\right)-1}
$$

where $O_{1}$ denotes the rotor inlet where reference conditions $p_{01}$ and $t_{01}$ are constant, and ()$_{3}$ denotes the stator exit. The stage efficiency is plotted as a function

\begin{tabular}{|c|c|c|c|}
\hline \multirow{2}{*}{$\begin{array}{c}\text { adiabatic } \\
\text { efficiency }\end{array}$} & \multicolumn{3}{|c|}{ Averaging Scheme } \\
\cline { 2 - 4 } & energy & momentum & area \\
\hline unsteady & $\mathbf{0 . 8 8 0 3 2}$ & 0.87696 & 0.87447 \\
\hline steady & $\mathbf{0 . 8 7 8 5 8}$ & 0.86964 & 0.85904 \\
\hline difference & $\mathbf{0 . 0 0 1 7 4}$ & 0.00732 & 0.01543 \\
\hline
\end{tabular}

Table 1: Comparison of stage adiabatic efficiencies.

\begin{tabular}{|c|c|c|c|}
\hline \multirow{2}{*}{$\begin{array}{c}\text { stator loss } \\
\text { coefficient }\end{array}$} & \multicolumn{3}{|c|}{ Averaging Scheme } \\
\cline { 2 - 4 } & energy & momentum & area \\
\hline unsteady & 0.02616 & 0.03236 & 0.03582 \\
\hline steady & 0.02809 & 0.03042 & 0.03256 \\
\hline difference & -0.00193 & 0.00194 & 0.00326 \\
\hline
\end{tabular}

Table 2: Comparison of stator loss coefficients.

of blade passing interval (time) in figure 11. The unsteady efficiency varies by about \pm 1 point over a cycle.

The time average of the unsteady solution is also shown in figure 11 and is compared with the efficiency predicted using the steady EAS calculation. The two results agree within 0.02 points in efficiency.

Table 1 compares the stage adiabatic efficiencies calculated using each of the three averaging schemes. The EAS gives the highest efficiency and the best agreement between the steady and unsteady results whereas the AAS gives the lowest efficiency and the worst agreement.

The stator loss coefficient was also calculated from the steady and unsteady calculations using the three averaging schemes, and the results are presented in table 2 . The loss coefficient is defined by

$$
\omega=\frac{p_{02}-p_{03}}{p_{02}-p_{2}}
$$

where ()$_{2}$ denotes the stator inlet. The stator loss coefficient is difficult to compute from the unsteady calculation because the losses are referenced to interbladerow quantities $p_{2}$ and $p_{02}$ which are themselves unsteady. Here the EAS was used to define the stator inlet state 2 , then the three averaging schemes were used to compute the loss at 3 from both the unsteady and steady solutions. The EAS gives the lowest stator loss and the AAS gives the highest. The steady losses are slightly higher than the time-averaged unsteady losses using the EAS but are lower than the unsteady losses using the MAS or AAS. The EAS and MAS both give fairly close agreement between the unsteady and steady calculations. There is a somewhat larger difference between the unsteady and steady losses calculated with the AAS.

\section{SUMMARY}

Three schemes for averaging computed flowfields in turbomachinery, the momentum (MAS), energy 
(EAS), and area (AAS) averaging schemes, were described and compared. The MAS conserves global mass, momentum, and energy. For 2-D adiabatic flow it is equivalent to a mixed-out average, giving the flow properties after the wakes have mixed out far downstream. It provides the correct available thrust but tends to provide low efficiencies and high losses. The EAS replaces conservation of axial momentum with an integration of the ideal total enthalpy. It is intended to give a good measure of the local total pressure and total temperature, quantities needed in the calculation of efficiency and loss. It generally gives the best comparison with experimental data. The AAS integrates quantities often measured experimentally: static presure, total pressure, and total temperature. It has little other physical significance and gives the lowest efficiency and highest loss of the three schemes.

The three averaging schemes were used as the basis of a steady averaging-plane analysis of a transonic fan. The rotor and stator were analyzed independently with average rotor exit conditions specified at the upstream boundary of the stator. The averaging-plane results were compared to an unsteady rotor-stator interaction solution which did not require averaging between the blade rows.

Several interesting physical phenomena were noted in the unsteady solution. Large pressure fluctuations which could contribute to noise generation were seen on the stator blades. Despite the large pressure fluctuations the averaging-plane analysis matched the timeaveraged pressure distribution almost exactly, regardless of the averaging scheme used. The rotor wakes migrated towards the stator pressure surface. Although the effects of wake migration cannot be modeled with a averaging-plane analysis, the overall stage efficiency and stator loss coefficient were predicted fairly well with the averaging-plane analysis based on the EAS.

Several unresolved issues remain concerning averaging schemes. First, many other schemes can be devised, such as mass-averaging total pressure for comparison to experimental data, or averaging entropy to estimate losses. These schemes must be evaluated for their particular applications. Second, the fan stage analyzed has a large interblade spacing, so the results might not hold for a stage with stronger acoustic coupling. Third, the schemes can be extended to 3-D by addition of a spanwise integral, but it is not immediately clear what quantity to integrate. Finally, it is also unclear how to average unsteady solutions for the best comparison with steady solutions or with low frequency response probe data.

\section{REFERENCES}

[1] Chima, R. V., "Viscous Three-Dimensional Calculations of Transonic Fan Performance," in CFD Techniques for Propulsion Applications, AGARD
Conference Proceedings No. CP-510, AGARD, Neuilly-Sur-Seine, France, Feb. 1992., pp 21-1 to 21-19.

[2] Adamczyk, J. J., Mulac, R. A., Celestina, M. L., "A Model for Closing the Inviscid Form of the Average Passage Equations," ASME J. Turbomachinery, Vol. 108, 1986, pp 180-186.

[3] Dawes, W. N., "Towards Improved Throughflow Capability: The Use of 3D Viscous Flow Solvers in a Multistage Environment," ASME Paper 90GT-19, 1990.

[4] Denton, J. D., "The Calculation of Three Dimensional Viscous Flow Through Multistage Turbomachines," ASME Paper 90-GT-19, 1990.

[5] Ni, R.-H. R., Bogoian, J. C., "Prediction of a 3D Multistage Turbine Flow Field Using a MultipleGrid Euler Solver," AIAA Paper 89-0203, 1989.

[6] Rai, M. M., "Unsteady Three-Dimensional Navier-Stokes Simulations of Turbine RotorStator Interaction," AIAA Paper 87-0258, 1987.

[7] Hall, E. J., Delaney, R. A., "Investigation of Advanced Counterrotation Blade Configuration Concepts for High Speed Turboprop Systems, Task 5 Unsteady Counterrotation Ducted Propfan Analysis Final Report," NASA CR-187126, Jan. 1993.

[8] Chen, J. P., Whitfield, D. L., "Navier-Stokes Calculations for the Unsteady Flowfield of Turbomachinery," AIAA Paper 93-0676, Jan. 1993.

[9] Gundy-Burlet, K. L., Rai, M. M., Stauter, R. C., Dring, R. P., "Temporally and Spatially Resolved Flow in a Two-Stage Axial Compressor: Part 2 Computational Assessment," ASME J. Turbomachinery, Vol. 113, 1991, pp 227-232.

[10] Jorgenson, P. C. E., Chima, R. V., "Explicit Runge-Kutta Method for Unsteady Rotor-Stator Interaction," AIAA J., Vol. 27, No. 6, June 1989, pp. 743-749.

[11] Jorgenson, P. C. E., Chima, R. V., "An Unconditionally Stable Runge-Kutta Method for Unsteady Flows," AIAA Paper 89-0205, 1989.

[12] Lewis, J. P., Delaney, R. A., Hall, E. J., "Numerical Prediction of Turbine Vane-Blade Aerodynamic Interaction," ASME J. Turbomachinery, Vol. 111, 1989, pp 387-393.

[13] Wyss, M. L., "Assessment of Averaging Techniques in Unsteady and Steady-State Turbomachinery Flow Solutions for a Transonic Fan Stage," M.S. Thesis, U. of Cincinnati Dept. of Aerospace Engr., Cincinnati, OH, 1992. 
[14] Hathaway, M. D., "Unsteady Flows in a SingleStage Transonic Axial-Flow Fan Stator Row," NASA TM-88929, 1986, and USAAVSCOM TR86-C-29, 1986.

[15] Suder, K. L., Hathaway, M. D., Okiishi, T. O., Strazisar, A. J., Adamczyk, J. J., "Measurements of the Unsteady Flow Field Within the Stator Row of a Transonic Axial-Flow Fan, I - Measurements and Anaysis Technique," ASME Paper 87-GT226, May, 1987.

[16] Hathaway, M. D., Suder, K. L., Okiishi, T. O., Strazisar, A. J., Adamczyk, J. J., "Measurements of the Unsteady Flow Field Within the Stator Row of a Transonic Axial-Flow Fan, II - Results and Discussion," ASME Paper 87-GT-226, May, 1987.

[17] Chima, R. V., "Explicit Multigrid Algorithm for Quasi-Three-Dimensional Viscous Flows in Turbomachinery," AIAA J. Propulsion and Power, Vol. 3, No. 5, Sept.-Oct. 1987, pp 397-405.

[18] Steger, J. L., and Sorenson, R. L., "Automatic Mesh-Point Clustering Near a Boundary in Grid Generation with Elliptic Partial Differential Equations," J. Comp. Phys., Vol. 33, No. 3, Dec. 1979, pp. $405-410$.

[19] Kerrebrock, J. L., Mikolajczak, A. A., "IntraStator Transport of Rotor Wakes and its Effects on Compressor Performance," ASME J. Engr. for Power, Vol. 92, Oct. 1970, pp 359-368.

[20] Valkov, T., Tan, C. S., "Computational Investigation of the Unsteady Flow and Its Control During Wake-Stator Interaction at High Reynolds Numbers," ASME Paper 93-GT-23, 1993. 
Public reporting burden tor this collection of information is estimated to average 1 hour per response, inctuding the time for reviewing instructions, searching existing data sources, gathering and maintaining the data needed, and completing and reviewing the collection of information. Send comments regarding this burden estimale or any other aspect of this collection of information, including suggestions for reducing this burden, to Washington Headquarters Services, Directorate for Information Operations and Reports, 1215 Jefierson Davis Highway, Suite 1204, Aflington, VA 22202-4302, and to the Office of Management and Budget, Paperwork Peduction Project (0704-0188), Washington, DC 20503.

\begin{tabular}{|l|c|c|}
\hline 1. AGENCY USE ONLY (Leave blank) & $\begin{array}{r}\text { 2. REPORT DATE } \\
\text { July } 1993\end{array}$ & $\begin{array}{r}\text { 3. REPOAT TYPE AND DATES COVERED } \\
\text { Technical Memorandum }\end{array}$
\end{tabular}

\section{TITLE AND SUBTITLE}

5. FUNDING NUMBERS

Averaging Techniques for Steady and Unsteady Calculations of a Transonic Fan Stage

6. AUTHOR(S)

WU-535-05-10

M.L. Wyss, R.V. Chima, and D.L. Tweedt

\section{PERFORMINg ORganIZATION NAME(S) AND ADDRESS(ES)}

National Aeronautics and Space Administration

Lewis Research Center

Cleveland, Ohio 44135-3191
8. PERFORMING ORGANZATION REPORT NUMBER

E-7950
9. SPONSORING/MONTORING AGENCY NAME(S) AND ADDRESS(ES)

National Aeronautics and Space Administration

Washington, D.C. 20546-0001
10. SPONSORING/MONITORING AGENCY REPORT NUWBER

NASA TM-106231

AIAA-93-3065

11. SUPPLEMENTARY NOTES

Prepared for the 24th AIAA Fluid Dynamics Conference sponsored by the American Institute of Aeronautics and Astronautics, Orlando, Florida, July 6-9, 1993. M.L. Wyss, University of Cincinnati, Cincinnati, Ohio 45221 and R.V. Chima and D.L. Tweedt, NASA Lewis Research Center. Responsible person, R.V. Chima, (216) 433-5919.

12a. DISTRIBUTION/AVAILABILTYY STATEMENT

Unclassified - Unlimited

Subject Category 01

\section{ABSTRACT (Maximum 200 words)}

It is often desirable to characterize a turbomachinery flow field with a few lumped parameters such as total pressure ratio or stage efficiency. Various averaging schemes may be used to compute these parameters. This paper describes and compares the momentum, energy, and area averaging schemes. The schemes were compared for two computed solutions of the midspan section of a transonic fan stage: a steady averaging-plane solution in which average rotor outflow conditions were used as stator inflow conditions, and an unsteady rotor-stator interaction solution. The solutions were computed on identical grids using similar Navier-Stokes codes and an algebraic turbulence model. The unsteady solution is described, some unsteady flow phenomena are discussed, and the steady pressure distributions are compared. Despite large unsteady pressure fluctuations on the stator surface, the steady pressure distribution matched the average unsteady distribution almost exactly. Stator wake profiles, stator loss coefficient, and stage efficiency were computed for the two solutions with the three averaging schemes and are compared. In general, the energy averaging scheme gave good agreement between the averaging-plane solution and the time-averaged-unsteady solution, even though certain phenomena due to unsteady wake migration were neglected.

\begin{tabular}{|l|l|}
\hline 14. SUBJECT TERMS \\
Multistage turbomachinery; Averaging techniques; Rotor/Sta \\
Unsteady flow \\
$\begin{array}{c}\text { 17. SECURITY CLASSIFICATION } \\
\text { OF REPORT } \\
\text { Unclassified }\end{array}$ & $\begin{array}{c}\text { 18. SECURTY CLASSIFICATION } \\
\text { OF THIS PAGE } \\
\text { Unclassified }\end{array}$ \\
\hline
\end{tabular}

